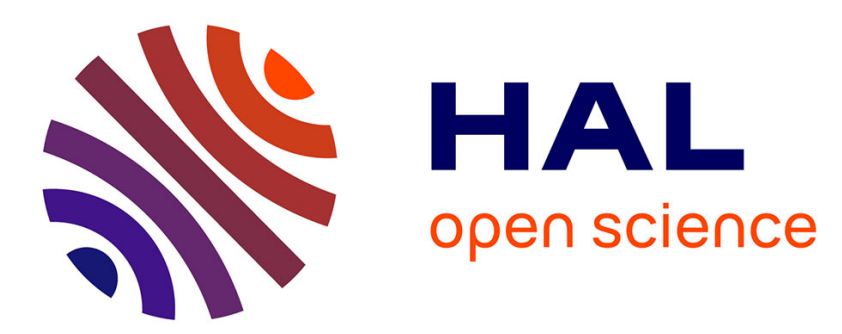

\title{
Compression Tests of Polycrystalline $\alpha$-Iron up to High Strains Over a Large Range of Strain Rates
}

\author{
D. Ostwaldt, J. Klepaczko, P. Klimanek
}

\section{To cite this version:}

D. Ostwaldt, J. Klepaczko, P. Klimanek. Compression Tests of Polycrystalline $\alpha$-Iron up to High Strains Over a Large Range of Strain Rates. Journal de Physique IV Proceedings, 1997, 07 (C3), pp.C3-385-C3-390. 10.1051/jp4:1997367 . jpa-00255524

\section{HAL Id: jpa-00255524 https://hal.science/jpa-00255524}

Submitted on 1 Jan 1997

HAL is a multi-disciplinary open access archive for the deposit and dissemination of scientific research documents, whether they are published or not. The documents may come from teaching and research institutions in France or abroad, or from public or private research centers.
L'archive ouverte pluridisciplinaire HAL, est destinée au dépôt et à la diffusion de documents scientifiques de niveau recherche, publiés ou non, émanant des établissements d'enseignement et de recherche français ou étrangers, des laboratoires publics ou privés. 
J. PHYS IV FRANCE 7 (1997)

Colloque C3, Supplément au Journal de Physique III d'août 1997

\title{
Compression Tests of Polycrystalline $\alpha$-Iron up to High Strains Over a Large Range of Strain Rates
}

\author{
D. Ostwaldt, J.R. Klepaczko and P. Klimanek \\ Freiberg University of Mining and Technology, Institute of Physical Metallurgy, Gustav Zenner str. 5, \\ 09596 Freiberg, Germany
}

\begin{abstract}
Compression tests have been performed on polycrystalline b.c.c. iron in order to study dynamic plasticity and evolution of microstructure. The paper describes the experimental setups and the results obtained at $295 \mathrm{~K}$ for strain rates $10^{-3} \mathrm{~s}^{-1} \leq \dot{\varepsilon} \leq 10^{4} \mathrm{~s}^{-1}$ and plastic strains up to large values $\varepsilon-0.8$. Stress-strain diagrams have been found for all conditions mentioned. The rate dependence of stress indicates two regions of the rate sensitivity. The low strain rate range shows only slight rate sensitivity, but it increases rapidly at strain rates above $10^{3} \mathrm{~s}^{-1}$. This effect is accompanied by formation of twins. Optical and TEM micrographs confirm these observations. Dislocation density and microhardness have been also measured.
\end{abstract}

Résumé: Les essais de compression ont été effectués sur du fer polycristallin pour étudier la plasticité dynamique et l'évolution de microstructure. L'article décrit les bancs d'essais et les résultats obtenus à $295 \mathrm{~K}$ sur une grande plage de vitesse de déformation $10^{-3} \mathrm{~s}^{-1} \leq \varepsilon^{*} \leq 10^{4} \mathrm{~s}^{-1}$ et aux grandes déformations $\varepsilon$ (jusqu'à $\varepsilon \sim 0.8$ ). Les courbes contrainte-déformation correspondantes ont été déterminées. La dépendance de la vitesse de déformation sur la contrainte indique deux régions de sensibilité à la vitesse. Le domaine de basses vitesses montre seulement une faible influence de la sensibilité à la vitesse, mais celle-ci augmente rapidement aux vitesses de déformation plus élevées au-delà de $10^{4} \mathrm{~s}^{-1}$. Cet effet est accompagné par la formation de macles. Les micrographies optiques et par MET confirment ces observations. La densité de disiocation et la micro dureté ont été aussi mesurées.

\section{INTRODUCTION}

Materials behaviour and evolution of microstructure during plastic deformation strongly depend on strain rate. Dynamic loading of materials may lead to deformation inhomogeneities caused by

- inertia effects and wave propagation as consequences of the loading pulse [1],

- adiabatic heating due to the very short deformation time (usually less than $500 \mu \mathrm{s}$ ) and

- increasing rate sensitivity following a transition from thermally activated to completely damped dislocation movement [2].

Generally, two regions of strain rate sensitivity exist. At rates $\dot{\varepsilon}<\left(10^{2} \ldots 10^{3}\right) \mathrm{s}^{-1}$, the strain rate has only a slight influence on the flow stress. In this range, the stress is proportional to the logarithm of strain rate. Above $10^{3} \mathrm{~s}^{-1}$ the strain rate sensitivity increases rapidly and the stress is a linear function of strain rate [3]. Usually, the effects just mentioned complicate the acquisition and interpretation of data on microstructural evolution. Therefore, the performance of such experiments requires not only equipment of high technical standard but also a careful monitoring and analysing of raw experimental data.

\section{EXPERIMENTAL DETAILS}

\subsection{Experimental Setups for High Strain Rate Compression Tests}

\subsubsection{Split Hopkinson Pressure Bar (SHPB) and Direct Impact}

SHPB is a testing machine which is most frequently used. Its principle is based on KOLSKY idea [4] and the setup was later improved by LINDHOLM [5]. Compression, tension and torsion tests can be realized with this scheme. Fig. 1 shows the scheme of SHPB for compression tests. Because this system is widly used a detailed description is emitted here. Strain rattes between $10^{7} \mathrm{~s}^{-1}$ and $10^{+1} \mathrm{~s}^{-1}$ are accessible. Most frequently experiments are performed at room temperature. Testing at elevated temperatures requires extensive 
corrections. Cylindrical or tubular specimens with a height-diameter-ratio smaller than 1.0 are used. Determination of strain and compression stress in a specimen is done by means of strain gages cemented on the elastic bars via measurements of the incident, reflected and transmitted waves.

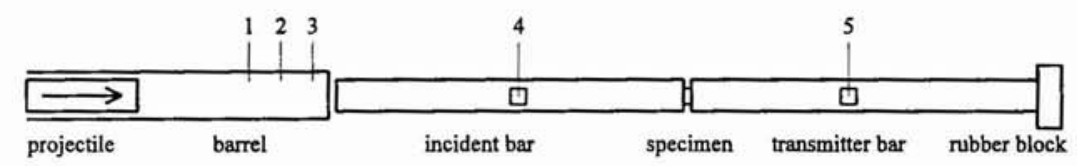

$1,2,3$ - photodiodes for measuring of flight time (to determine impact velocity of projectile) 4,5 - strain gages

Figure 1: Schematic layout of split Hopkinson pressure bar used in LPMM-Metz, Ø $10 \mathrm{~mm}$ and $\varnothing 20 \mathrm{~mm}$.

A disadvantage of the SHPB is the limited strain rate. Because it is not allowed to exceed the yield point of the bar material the impact velocity of projectile has an upper limit. To reach still higher strain rates the incident bar has been removed. The projectile directly strikes the specimen (direct impact) [6]. The procedure and calculations are similar to these of SHPB test. However, the measurement of strain has to be performed in another way. Two non-contact displacement gages record displacements $\delta_{A}(t)$ und $\delta_{B}(t)$ of the both ends of specimen, Fig. 2 . For that, the system requires sharp white-black fields to be monitored, realized by black painted ends of projectile and transmitter bar and white painted specimen. A black screen is installed behind the specimen to minimize external influences.

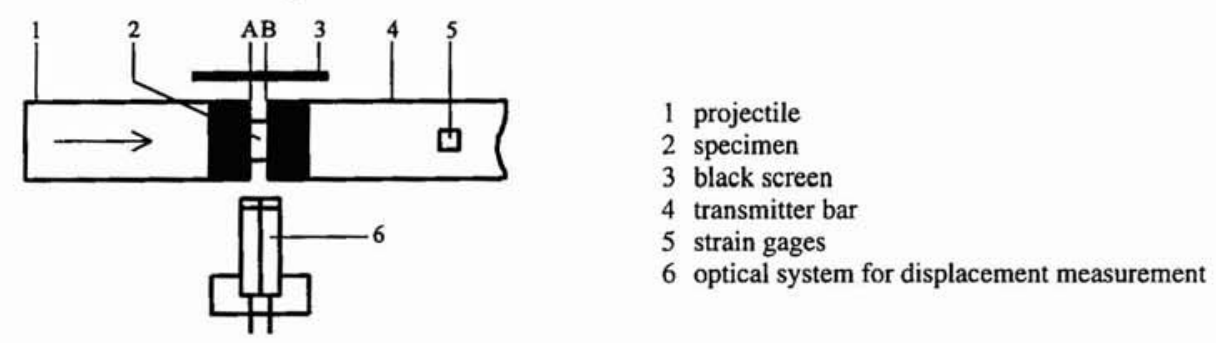

Figure 2: Principle of displacement measurement in the direct impact test developed in LPMM-Metz.

\subsubsection{Ballistic Test System}

A ballistic test system was constructed in IPM-Freiberg to perform compression tests at high strain rates and in a wide temperature range [7,8], Fig. 3. As in the case of SHPB and direct impact, a projectile is accelerated in a vertically positioned barrel by expansion of a compressed gas. Its velocity is determined by measurement of the flight time using photodiodes installed at the end of the barrel. The specimen is inside a heat chamber. Before compression test at elevated temperature, the chamber (with the specimen and punch)

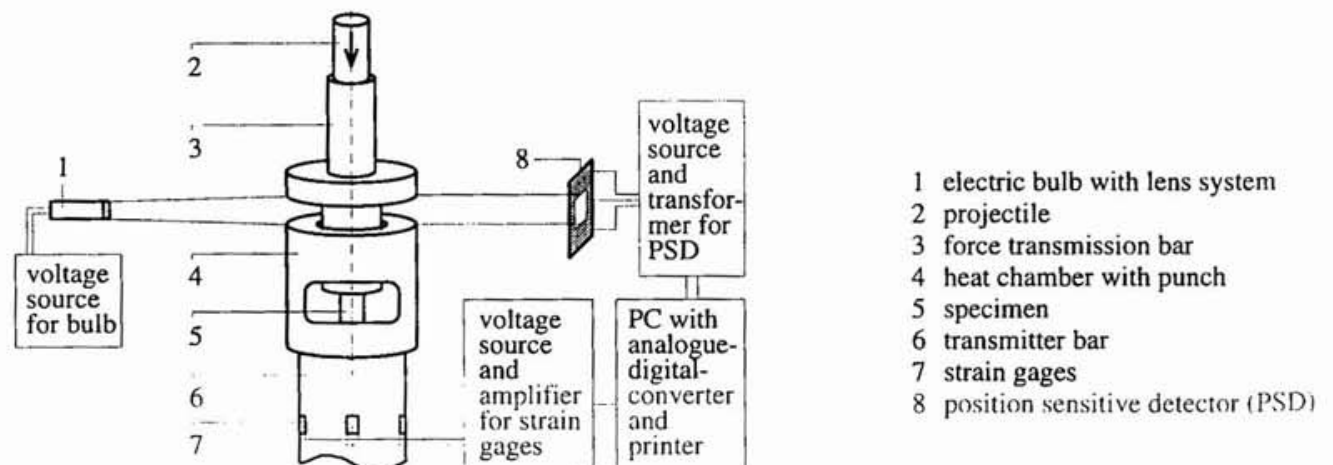

Figure 3: Arrangement of the ballistic plastometer (used in IPM-Freiberg) and its components at the time of impact. 
is heated up in an external furnace. To freeze the microstructure of the deformed material, it is necessary to eject the specimen immediately after the compression test into a water tank. The measurement of displacement is performed by an optical setup. A photo-sensitive detector (PSD) records the displacement of the punch. The compression force is determined by measurement of the elastic strain of the transmitter bar using strain gages. A calibration procedure is required to transform the measured voltage into force. The upper end of the transmitter bar is cooled by water to protect the strain gages from the high temperatures and to maintain the validity of calibration. Compression tests at strain rates between $\sim 7 \cdot 10^{2} \mathrm{~s}^{-1}$ and $\sim 1 \cdot 10^{4} \mathrm{~s}^{-1}$ and temperatures from room temperature up to $1000^{\circ} \mathrm{C}$ can be performed with this device. The insert of space washers between heat chamber and punch allows to stop the compression test at predetermined strains. Because of the large specimen dimensions the investigation of microstructure evolution is possible without any problem.

\subsection{Specimens and deformation parameters}

An iron bar ( $\mathrm{Fe} 99.6 \%)$ was rolled at $950^{\circ} \mathrm{C}$ to a diameter of $12 \mathrm{~mm}$. Specimens in the form of small discs (initial height $\mathrm{h}_{0}=3 \mathrm{~mm}$, initial diameter $\left.\mathrm{d}_{0}=6 \mathrm{~mm}\right)$ and cylinders $\left(\mathrm{h}_{0}=10.5 \mathrm{~mm}, \mathrm{~d}_{0}=7 \mathrm{~mm}\right.$, used in the ballistic test system) have been machined from this rod. The rolling was followed by annealing ( 20 minutes at $1000^{\circ} \mathrm{C}$ ). An initial state of microstructure with recrystallized grains was obtained as the result of this heat treatment. The average grain size is about $15 \mu \mathrm{m}$.

Compression tests have been performed at room temperature over a large range of strain rates. For testing at low and medium rates servohydraulic universal testing machines were used. Before testing the specimens were lubricated with $\mathrm{MoS}_{2}$. Consequently the effect of friction between specimen surfaces and plates was reduced. The deformation parameters are summarized in Table 1.

Table 1: Deformation parameters for compression tests of Armco iron

\begin{tabular}{|l|l|l|}
\hline testing setup & maximum strain $\varepsilon$ & average strain rate $\dot{\varepsilon}\left[\mathrm{s}^{-1}\right]$ \\
\hline universal testing machine MTS & $0.20,0.70$ & $0.005,5$ \\
\hline high-speed universal testing machine Zwick & $0.35,0.80$ & $0.005,0.07,7,130$ \\
\hline ballistic plastometer & 0.80 & 1800 \\
\hline SHPB & $0.35,0.80$ & 2000,4200 \\
\hline direct impact & $0.40,0.90$ & 7000,9000 \\
\hline
\end{tabular}

\section{RESULTS AND DISCUSSION}

\subsection{Stress-Strain Diagrams and Strain Rate Sensitivity}

The stress-strain diagrams are shown in Fig. 4. Correction for friction has been perfomed according to equation (1) [9].

$$
\sigma_{n(\mathrm{corr})}=\sigma_{n}\left[1-\mu \frac{d_{0}}{h_{0}}\left(1-\varepsilon_{n}\right)^{-3 / 2}\right]
$$

$\left(\sigma_{\text {ntcore }}\right), \sigma_{n}:$ nominal stress with/without correction of friction, $\mu$ : coefficient of friction, $\varepsilon_{n}:$ nominal strain)

Elimination of the machine rigidity was introduced into the data analysis. For the tests under dynamic conditions, the measured stress is not influenced by inertia effects. This is caused by the very small initial height of the specimens (SHPB, direct impact) and a comparatively low dynamic strain rate (ballistic plastometer).

For strain rates above $7 \mathrm{~s}^{-1}$, the stress level is reduced by influence of adiabatic heating. For this reason, the 
adiabatic curves (Fig. 4a) were converted into isothermal ones (Fig. 4b) using the temperature sensitivity of flow stress. The curves show typical behaviour of metals deformed at low homologous temperatures. The isothermal curves increase monotonously, but the adiabatic curves suggest a steady state for higher strain rates caused by temperature softening. The stress level seems to be high in comparison with the expected values for polycrystalline iron. However, it is caused by the heat treatment and the resulting fine-grained structure with a relative high dislocation density. No yield point phenomenon has been found. This is in contrast to the results of other authors $[9,10]$. However, it could be explained by the very small specimen dimensions, which can suppress the appearence of the Lüders band.
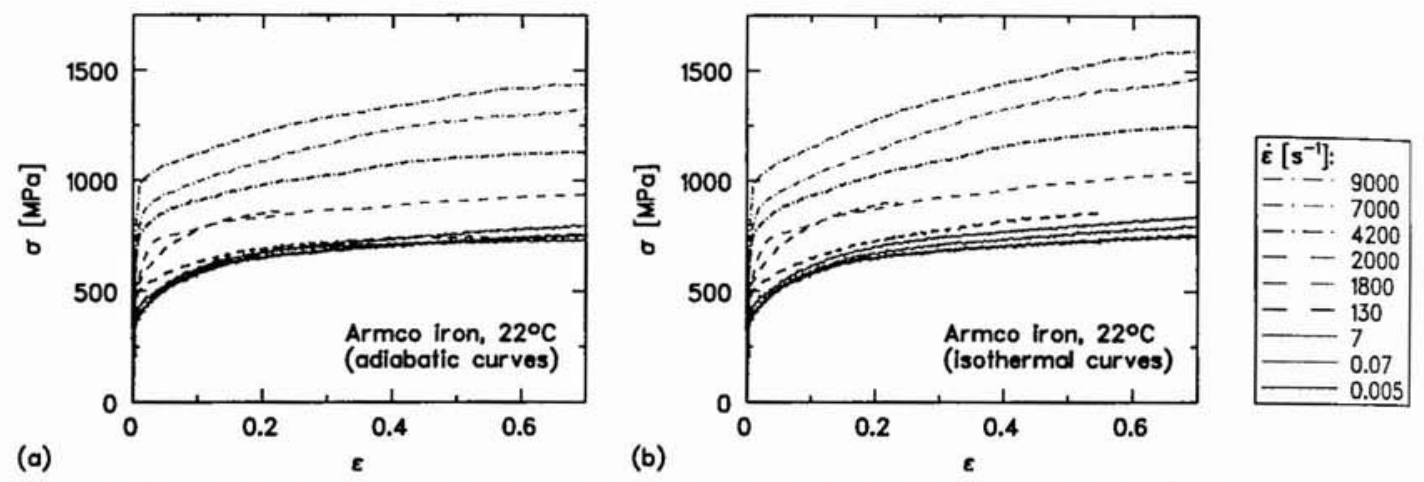

Figure 4: Stress-strain diagrams obtained at room temperature and strain rates from $5 \cdot 10^{-3} \mathrm{~s}^{-1}$ up to $9 \cdot 10^{3} \mathrm{~s}^{-1}$.

Fig. 5 gives information about the rate sensitivity of the flow stress. It is important to note that in this paper, unlike as in [3], the rate sensitivity at constant strain rather than at constant structure is considered. Therefore, it cannot be compared with values determined in jump tests, but it is suitable to illustrate the effect of strain rate on stress. At low rates there is only a slight increase of the stress. However, it becomes a sharp increase at rates above $\left(10^{2} \ldots 10^{3}\right) \mathrm{s}^{-1}$. On the other hand, the strain hardening rate does not depend on strain rate. The isothermal curves are shifted against one another in parallel.

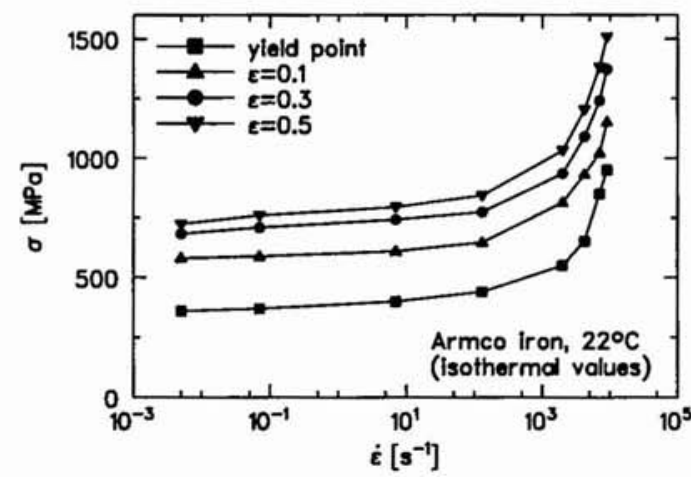

Figure 5: Strain rate sensitivity of flow stress for Armco iron at $22^{\circ} \mathrm{C}$.

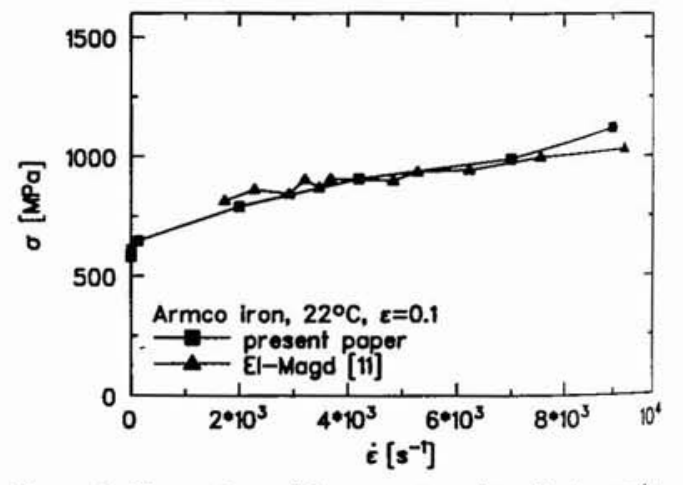

Figure 6: Comparison of the present results with the results of other authors.

A number of results concerning deformation tests on $\alpha$-iron have been published in the last decades. However, comparison with different results is difficult because of very different testing conditions (deformation mode, material purity and history, specimen dimensions, etc.). Therefore, the present results can be directly compared only with the results published in [11]. The fit of the stress level is satisfactory. Fig. 6.

\subsection{Evolution of Microstructure}

Following the compression tests the deformed specimens were examined with respect to evolution of 
microstructure. For that reason, the specimens were cut in two ways, either parallel to the specimen axis (and deformation direction, respectively) or perpendicular to this. Dislocation densities (at the perpendicular section) and microhardness along the cylinder axis (parallel section) were measured. X-ray diffraction was used for determination of dislocation density. TEM investigations were also performed to estimate more precisely the evolution of the dislocation arrangement.

\subsubsection{Metallography and TEM Investigations}

The optical micrographs show a deformed grain microstructure typical for metals compressed at low homologous temperatures. No significant influence of the strain rate can be observed. For a better visualization of microbands or shear bands, the observation has been carried out with interference contrast microscopy. The deformed specimens contain intragranular deformation bands and intergranular shear bands. However, the density and the place of formation of these phenomena do not depend significantly on the stráin rate. A typical micrograph is shown in Fig. 7.

Metallographic observations cannot give information about changes of substructures. For that reason TEM foils were investigated. The initial state is characterized by a relatively high dislocation density. The deformed states have a higher dislocation density which corresponds to the applied plastic strain. Because the density exceeds the resolution power of the TEM method there is no possibility to determine the dislocation density exactly. Formation of dislocation cells (subgrains) could not been observed. In contrast to the specimens deformed under quasistatic conditions the dynamically compressed specimens have twins. Twinning proves to be an additional deformation mechanism at high strain rates. It occurs at strain rates above $\left(10^{1} \ldots 10^{2}\right) \mathrm{s}^{-1}$. The density of twins increases with increasing strain rate. The twins are shortly fragmented because the high dislocation density causes a rapid decrease of the driving force of the twin growth. These observations are in accordance with the results published in [12]. Figs. 8 and 9 show TEM micrographs for specimens deformed at low and high strain rates.

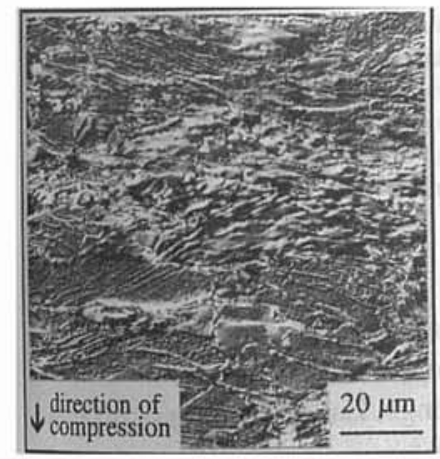

Figure 7: Micrograph of Armco iron $\left(22^{\circ} \mathrm{C} / 7 \mathrm{~s}^{-1} / \varepsilon=0.8\right)$.

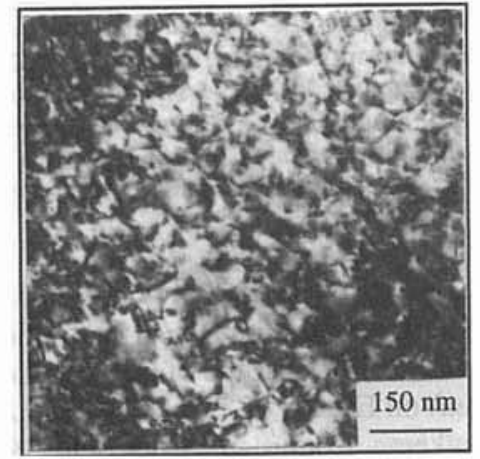

Figure 8: TEM micrograph of Armco iron $\left(22^{\circ} \mathrm{C} / 7 \mathrm{~s}^{-1 / \varepsilon}=0.8\right)$

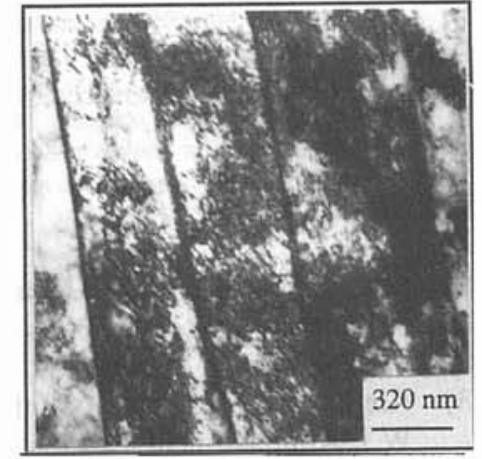

Figure 9: TEM micrograph of Armco iron $\left(22^{\circ} \mathrm{C} / 4200 \mathrm{~s}^{-1} / \varepsilon=0.8\right)$.

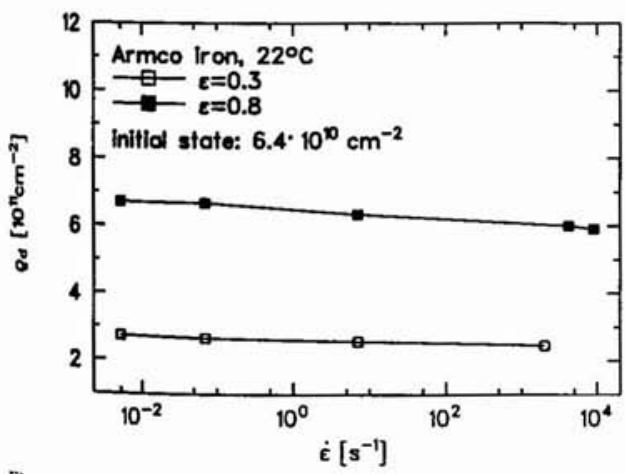

Figure 10: Total dislocation density in dependence on strain rate (Armco iron, $22^{\circ} \mathrm{C}$ ).

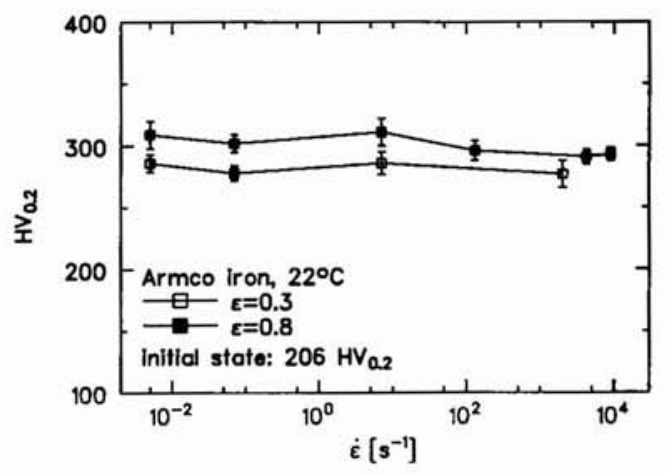

Figure 11: Microhardness in the specimen centre as a function of strain rate (Armco iron. $22^{\circ} \mathrm{C}$ ). 


\subsubsection{Total Dislocation Density and Microhardness}

The total dislocation density $\rho_{d}$ can be determined by analysis of X-ray diffraction line broadening [13,14, 15]. The results are summarized in Fig. 10. The initial state has dislocation density of about $6 \cdot 10^{10} \mathrm{~cm}^{2}$. During compression test it increases up to $7 \cdot 10^{11} \mathrm{~cm}^{-2}$. The strain rate has only a small influence on dislocation density. There is a slight decrease of dislocation density with increasing strain rate. This could be caused by effect of adiabatic heating and dynamic recovery processes. This is in accordance with the microhardness measurements, Fig. 11.

\section{CONCLUSIONS}

Compression tests at room temperature has been performed on polycrystalline iron over a wide range of strain rates. For this purpose various experimental setups were used. The results obtained with split Hopkinson pressure bar and ballistic plastometer are in good agreement.

In accordance with expectations the flow stress but not the strain hardening rate is strongly affected by the strain rate. For strain rates above $7 \mathrm{~s}^{-1}$ the $\sigma(\varepsilon)$ curves suggest a steady state caused by adiabatic heating. The isothermal stress-strain curves increase monotonously.

For strain rates higher than a critical value, twinning occurs as an additional deformation mechanism. The density of twins increases with increasing strain rate. However, an increase of strain rate does not cause changes in microstructural evolution, described by dislocation density and microhardness. On the contrary, a slight decrease of these values has been observed. This could be caused by adiabatic heating followed by dynamic recovery processes.

\section{ACKNOWLEDGEMENT}

The authors are grateful for the financial support by the Volkswagen-Stiftung. The French side has been supported by variety of sources, mainly $C N R S$.

\section{REFERENCES}

[1] Malinowski, J.Z., J.R. Klepaczko, Int. J. Mech. Sci. 28 (1986) 381

[2] Follansbee, P.S. et al., Proc. 3rd Conf. on the Mechanical Properties at High Rates of Strain, Oxford, 9.-12.4.1984, J. Harding Ed. (Conf. Ser. 70, Institute of Physics, London, 1984) 71

[3] Klepaczko, J.R., Proc. 1st Int. Conf. on Effects of Fast Transient Loadings, Lausanne, 26.-27.8.1987, W.J. Ammann et al. Eds. (A.A.Balkema, Rotterdam/Brookfield, 1988) 3

[4] Kolsky, H., Proc. Royal Soc. B 62 (1949) 676

[5] Lindholm, U.S., J. Mech. Phys. Solids 12 (1964) 317

[6] Dharan, C.K.H., F.E. Hauser, Exp. Mech. 10 (1970) 370

[7] Trinks, U., PhD (TU Bergakademie Freiberg, 1991) 30

[8] Ostwaldt, D. et al., Mat.-wiss. u. Werkstofftech. 27 (1996) 417

[9] Dingley, D.J., D. McLean, Acta Met. 15 (1967) 885

[10] Klepaczko, J.R., Int. J. Solids Structures 5 (1969) 533

[11] El-Magd, E. et al., Mat.-wiss. u. Werkstofftech. 20 (1989) 42

[12] Behler, F.J., B.O. Reinders, Proc. 1st Int. Conf. on Impact Loading and Dynamic Behaviour of Materials, Bremen 1987, C.Y. Chiem et al. Eds. (DGM-Informationsgesellschaft, Oberursel 1988) 677

[13] Krivoglaz, M.A. et al., Fizika metall. metalloved. 55 (1983) 5

[14] Klimanek, P., in: J. Hasek (Ed.), X-ray and Neutron Structure Analysis in Materials Science, Plenum Press, New York (1989) 125

[15] Klimanek, P., J. de Physique IV, Colloque C7, suppl. J. de Physique III 3 (1993) 2149 